\title{
APLIKASI PENILAIAN KINERJA KARYAWAN MENGGUNAKAN METODE SMART (SIMPLE MULTI-ATTRIBUTE RATING TECHNIQUE)
}

\author{
Muhammad Auliya $\mathbf{B}^{1}$, Yan Watequlis $\mathbf{S}^{2}$, Imam Fahrur $\mathbf{R}^{3}$ \\ ${ }^{1,2}$ Teknik Elektro, Teknik Informatika, Politeknik Negeri Malang \\ auliya17bachtiar@gmail.com, ${ }^{2}$ yan ws@yahoo.com, ${ }^{3}$ imam.rozi@gmail.com
}

\begin{abstract}
Abstrak
Untuk meningkatkan kualitas kinerja karyawan pada BRI Syariah KC Malang, pihak manajemen melakukan suatu proses penilaian (evaluasi) kinerja setiap karyawan. Untuk membantu dan mempermudah pihak manajemen dalam melakukan proses penilaian dan menentukan kategori karyawan berprestasi untuk setiap bulannya, maka dibangun suatu aplikasi pendukung keputusan dengan kriteria penilaian yang telah ditentukan oleh pihak manajemen yaitu integritas, kerjasama, kreatif, pelayanan pelanggan, profesionalisme dan orientasi tujuan. Masalah penentuan karyawan berprestasi tergolong ke dalam masalah yang bersifat multiobjective (banyak tujuan yang ingin dicapai) dan multicriterias (ada banyak kriteria yang menentukan dalam mencapai keputusan tersebut). SMART (Simple Multi - Attribute Rating Technique) adalah metode pengambilan keputusan multi kriteria yang didasarkan pada teori bahwa setiap alternatif terdiri dari sejumlah kriteria yang memiliki nilai-nilai dan setiap kriteria memiliki bobot yang menggambarkan seberapa penting ia dibandingkan dengan kriteria lain. Proses penilaian kinerja karyawan tersebut dipermudah dengan mengimplementasikan metode SMART yang diaplikasikan ke dalam tampilan web sehingga proses perhitungan menjadi terkomputerisasi dan tidak lagi dilakukan secara manual. Aplikasi ini dirancang dan dikembangkan untuk melakukan perhitungan kinerja karyawan di BRI Syariah KC Malang dan sudah diujicobakan pada beberapa manajer bank tersebut. Berdasarkan hasil ujicoba tersebut dapat disimpulkan bahwa aplikasi ini sesuai dengan kebutuhan dan pedoman dari instansi tersebut dalam melakukan penilaian kinerja karyawan dengan menggunakan metode SMART.
\end{abstract}

Kata kunci : Karyawan, Multikriteria, Multiobjektif,SMART.

\section{Pendahuluan}

Sumber daya manusia atau karyawan merupakan salah satu faktor penting dari jalannya suatu organisasi/perusahaan.

Dalam perusahaan atau instansi yang memiliki karyawan dalam jumlah besar proses evaluasi (penilaian) kinerja karyawan relatif sering dilakukan sehingga perusahaan memerlukan prosedur yang baku dalam menetapkan persyaratan bagi seorang karyawan yang diukur dari kinerjanya dan dipilih menjadi karyawan yang berprestasi.

Beberapa masalah yang terjadi selama proses evaluasi (penilaian) kinerja karyawan diantaranya adalah subyektifitas dalam penilaian kinerja terutama jika beberapa karyawan yang ada memiliki kemampuan (dan berdasarkan pertimbangan lain) yang tidak jauh berbeda.

Penilaian secara kuantitatif sering kali dianggap mengecewakan dikarenakan sulitnya mengukur parameter yang ada.

Masalah yang muncul saat ini adalah jika proses evaluasi (penilaian) rumit yaitu yang terjadi sekarang umumnya adalah adanya karyawan yang langsung ditetapkan menjadi karyawan berprestasi yang hanya dilihat dari satu kriteria saja, tetapi dalam beberapa kriteria - kriteria yang lain karyawan tersebut belum tentu unggul, akan tetapi tetap mendapat kriteria karyawan berprestasi.

Bank BRI Syariah KC Malang untuk mengetahui kinerja para karyawannya, pihak manajemen melakukan suatu proses penilaian.

Namun dalam hal ini pihak manajemen belum bisa membuat suatu analisa-analisa yang efektif, mengingat dalam proses penilaian ini masih bersifat manual. Perhitungan nilai kinerja karyawan yang kurang efektif serta pendokumentasian proses penilaian tidak dilakukan dengan baik.

Dalam hal ini BRI Syariah KC Malangmemiliki beberapa faktor atau kriteria penilaian, yaituintegritas, kerjasama, kreatif, disiplin, pelayanan pelanggan, profesionalisme, hasil kerja dan orientasi tujuan.

Dengan banyaknya kriteria yang berpengaruh dalam menentukan karyawan berprestasi berdasarkan kinerja yang ingin dipilih maka hal ini tentunya akan mempersulit 
manajer operasional dalam menentukan pilihan yang tepat, sesuai dengan kriteria yang diinginkan.

Masalah ini tergolong kedalam masalah yang bersifat multiobjective (banyak tujuan yang ingin dicapai), dan multicriterias (ada banyak kriteria yang menentukan dalam mencapai keputusan tersebut).

Banyak metode Sistem Pendukung Keputusan yang dapat membantu permasalahan diatas. Salah satu metode tersebut adalah metode SMART (Simple Multi Attribute Rating Technique).

Metode SMART merupakan metode pengambilan keputusan untuk menyelesaikan masalah penentuan pilihan yang bersifat multiobjective diantara beberapa kriteria.

Untuk itu perlu dirancang sebuah aplikasi sistem pendukung keputusan dengan menggunakan metode Simple Multi - Attribute Rating Technique (SMART), sehingga nantinya akan dapat menghasilkan suatu analisa yang efektif dan efisien.

Hal inilah yang mendorong untuk mengadakan penelitian pada Bank BRI Syariah KC Malang dengan membuat Aplikasi Penilaian Kinerja Karyawan Menggunakan Metode SMART yang diharapkan dapat memberikan kemudahan - kemudahan dalam melakukan proses penilaian karyawan untuk menentukan kategori karyawan berprestasi.

\section{Metode}

\subsection{Metode Penelitian}

2.1.1Bahan dan Alat Perlengkapan.

Dalam penelitian ini penulis menggunakan bahan dan peralatan sebagai berikut ;

- Komputer/Laptop.

- Window 7.

- Xampp 3.2.1

- PHP 5 sebagai bahasa pemrograman.

- MySQL untuk database.

- Sublime sebagai Text Editor.

Prosedur Penelitian.

Prosedur yang dilakukan dalam pembuatan penelitian ini adalah sebagai berikut:

1) Pengumpulan Data.

a. Data Primer.

Pengumpulan data ini dilakukan secara langsung melalui wawancara langsung terhadap manajer operasional Bank BRI Syariah untuk menemukan atau mengindentifikasi data - data yang diperlukan dalam menunjang penulis dalam penyusunan skripsi ini.

b. Data sekunder.

Dengan cara mencari/menentukan landasan teori yang berkesesuaian bagi penyusunan skripsi ini, penulis membaca, memahami, mengutip, dan membuat kesimpulan dari bukubuku, jurnal maupun skripsi yang berkaitan dengan penelitian ini. Penulis juga melakukan pencarian dari beberapa situs internet untuk mengumpulkan informasi yang berhubungan dengan hal-hal yang dibahas.

\subsubsection{Analisis Kebutuhan}

Melakukan proses analisis terhadap kebutuhan sistem yang akan dibuat berdasarkan tipe pengguna sistem.

Kebutuhan sistem dimodelkan diagram usecase.

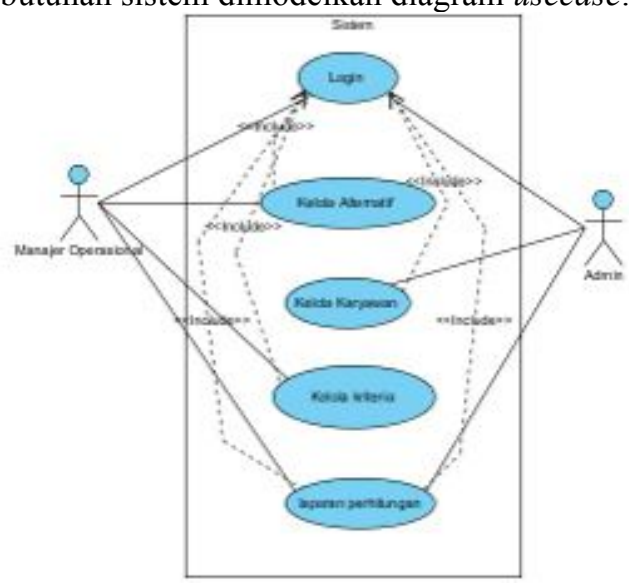

Gambar 2.1 Diagram Use Case

\subsubsection{Perancangan}

Aktifitas dalam tahap perancangan meliputi perancangan konteks diagram dari sistem. Berikut konteks diagram dari sistem yang akan dirancang:

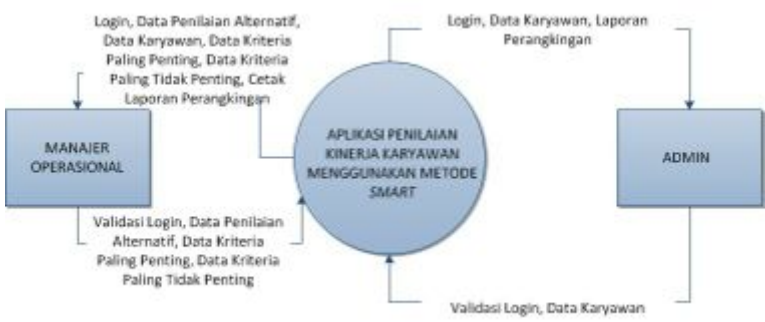

Gambar 2.2 Context Diagram

\subsection{Metode SMART}

SMART (Simple Multi - Attribute Rating Technique) merupakan metode pengambilan keputusan multi kriteria yang dikembangkan oleh 
(Edward, 1977). Teknik pengambilan keputusan multi kriteria ini didasarkan pada teori bahwa setiap alternatif terdiri dari sejumlah kriteria yang memiliki nilai - nilai dan setiap kriteria memiliki bobot yang menggambarkan seberapa penting ia dibandingkan dengan kriteria lain. Pembobotan ini digunakan untuk menilai setiap alternatif agar diperoleh alternatif terbaik.

SMART menggunakan linearadditivemodel untuk meramal nilai setiap alternatif. SMART merupakan metode pengambilan keputusan yang fleksibel. SMART lebih banyak digunakan karena kesederhanaanya dalam merespon kebutuhan pembuat keputusan dan caranya menganalisa respon. Analisa yang terlibat adalah transparan sehingga metode ini memberikan pemahaman masalah yang tinggi dan dapat diterima oleh pembuat keputusan.

Model fungsi utility linear yang digunakan oleh SMART adalah seperti berikut (Shepetukha, 2001).

$$
\text { Maximize }=\sum_{j=1}^{k} w_{j} \cdot u_{i j}, \forall i=1, \ldots, n
$$

Dimana:

- $\quad w_{j}$ adalah nilai pembobotan kriteria ke-j dari $k$ kriteria,

- $\quad u_{i j}$ adalah nilai utility alternatif $i$ pada kriteria $j$.

- Pemilihan keputusan adalah mengidentifikasi mana dari $\mathrm{n}$ alternatif yang mempunyai nilai fungsi terbesar.

- Nilai fungsi ini juga dapat digunakan untuk meranking $\mathrm{n}$ alternatif.

\subsubsection{Proses Permodelan SMART}

Edwards mendefinisikan ada sepuluh langkah dalam penyelesaian metode SMART yaitu:

1. Mengidentifikasi masalah keputusan. Pendefinisian masalah harus dilakukan untuk mencari akar masalah dan batasan - batasan yang ada. Keputusan seperti apa yang akan diambil harus didefinisikan terlebih dahulu, sehingga proses pengambilan keputusan dapat terarah dan tidak menyimpang dari tujuan yang akan dicapai. Pendefinisian pembuat keputusan (decision maker) dilakukan agar pemberian nilai terhadap kriteria dapat sesuai dengan kepentingan kriteria tersebut terhadap alternatif.

2. Mengidentifikasi kriteria - kriteria yang digunakan dalam membuat keputusan.
3. Mengidentifikasi alternatif - alternatif yang akan di evaluasi. Pada tahap ini akan dilakukan proses pengumpulan data.

4. Mengidentifikasi batasan kriteria yang relevan untuk penilaian alternatif. Perlu untuk membatasi nilai. Ini dapat dicapai dengan menghilangkan tujuan yang kurang penting. Edwards berpendapat bahwa tidak perlu memiliki daftar lengkap suatu tujuan. Lima belas dianggap terlalu banyak dan delapan dianggap cukup besar.

5. Melakukan peringkat terhadap kedudukan kepentingan kriteria. Dalam hal ini dinilai cukup mudah dibandingkan dengan pengembangan bobot. Hal ini perlu dilakukan untuk dapat memberikan bobot pada setiap kriteria. Karena bobot yang diberikan pada kriteria akan bergantung pada perangkingan kriteria.

6. Memberi bobot pada setiap kriteria. Pemberian bobot diberikan dengan nilai yang dapat ditentukan oleh user sendiri. Dalam hal ini akan dilakukan dua kali pembobotan yaitu berdasarkan kriteria yang dianggap paling penting dan berdasarkan kriteria yang dianggap paling tidak penting. Kriteria yang dianggap paling penting diberikan nilai 100 . Kriteria yang penting berikutnya diberikan sebuah nilai yang menggambarkan perbandingan kepentingan relatif ke dimensi paling tidak penting. Proses ini akan diteruskan sampai pemberian bobot ke kriteria yang dianggap paling tidak penting diperoleh.

7. Menghitung normalisasi bobot kriteria. Bobot yang diperoleh akan dinormalkan dimana bobot setiap kriteria yang diperoleh akan dibagikan dengan hasil jumlah setiap bobot kriteria. Normalisasi juga akan dilakukan berdasarkan kriteria yang paling penting dan kriteria yang paling tidak penting. Nilai dari dua normalisasi yang diperoleh akan dicari nilai rata - ratanya.

8. Mengembangkan single-attribute utilities yang mencerminkan seberapa baik setiap alternatif dilihat dari setiap kriteria. Tahap ini adalah memberikan suatu nilai pada semua kriteria untuk setiap alternatif. Dalam bidang ini seorang ahli memperkirakan nilai alternatif dalam skala $0-100$. Dimana 0 sebagai nilai minimum dan 100 sebagai nilai maksimum.

9. Menghitung penilaian/ utilitas setiap alternatif. Perhitungan ini dilakukandengan menggunakan fungsi yang telah ada yaitu: Maximize $\sum_{j=1}^{k} w_{j} \cdot u_{i j}$. Dimana $w_{j}$ adalah nilai pembobotan kriteria ke-j dari $k$ kriteria dan $u_{i j}$ adalah nilai utility alternatif $i$ pada kriteria $j$. Nilai $w_{j}$ diperoleh dari langkah dan nilai $u_{i j}$ diperoleh dari langkah 8 . 
10. Memutuskan. Nilai utilitas dari setiap alternatif akan diperoleh dari langkah 9. Jika suatu alternatif tunggal yang akan dipilih, maka pilih alternatif dengan nilai utilitas terbesar.

\subsection{Pengujian Sistem}

Melakukan pengujian terhadap hasil dan penggunaan metode SMART untuk mengetahui apakah metode tersebut dapat digunakan dan diterapkan pada mekanisme penilaian kinerja karyawan pada BRI Syariah KC Malang sesuai dengan sistem evaluasi yang ada.

\section{Hasil}

\subsection{Halaman Login}

Login digunakan untuk mengakses halaman sistem sesuai dengan otorisasi pengguna.

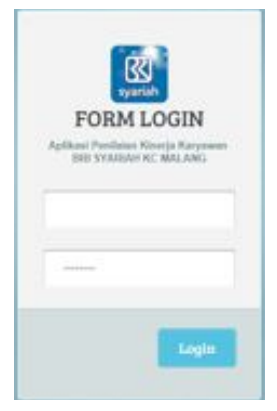

Gambar 3.1 Login

\subsection{Navigasi}

Panelnavigasi yang digunakan untuk pengguna sistem berpindah halaman satu ke halaman yang lain.

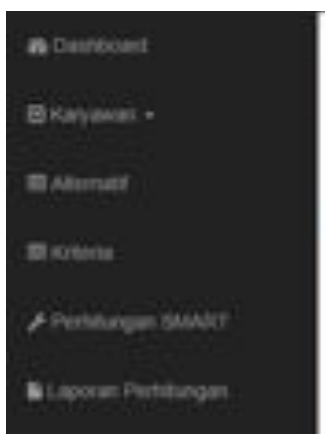

Gambar 3.2 Navigasi

\section{Pembahasan}

Pada pembahasan mengenai penggunaan metode SMART akan dijabarkan tahapan-tahapan penggunaan metode SMART dalam melakukan proses perhitungan terhadap perangkingan pemilihan kategori karyawan berprestasi dinilai dari kinerjanya. Penghitungan akan dilakukan pada pemilihan alternatif karyawan yang dipilih dan setiap kriteria yang dimiliki masing - masing alternatif dengan pembobotan yang telah dilakukan baik itu berdasarkan kriteria paling penting maupun kriteria paling tidak penting, hingga metode SMART dapat memberikan rekomendasi atau rujukan kepada manajer operasional untuk menentukan karyawan yang berhak menjadi karyawan berprestasi.

Kriteria yang digunakan untuk penilaian kinerja karyawan untuk menentukan kategori karyawan berprestasi untuk penelitian ini ada 6 yaitu, integritas, kerjasama, kreatif, pelayanan pelanggan, profesionalisme dan orientasi tujuan. Berikut langkah - langkah pengambilan keputusan pemilihan karyawan berprestasi menggunakan metode SMART (Simple Multi - Attribute Rating Technique):

1. Tentukan kriteria yang digunakan dalam penilaian kinerja karyawan.

2. Tentukan alternatif karyawan yang digunakan dalam proses perhitungan (minimal empat dan maksimal 9).

3. Rangking kriteria dan berikan bobot berdasarkan kriteria paling penting dan kriteria paling tidak penting. Kriteria paling penting berdasarkan observasi yang dilakukan yaitu kriteria integritas disetkan dengan bobot 100 dan kriteria paling tidak penting yaitu orientasi tujuan disetkan dengan nilai 10 .

4. Mencari nilai rata - rata bobot kriteria berdasarkan yang paling penting dan paling tidak penting.

5. Mencari normalisasi bobot dari kriteria paling penting dan kriteria paling tidak penting.

6. Memberilan bobot kepada setia p alternatif berdasark an setiap kriteria. Bobbt alternatif dalam skaía 50 - 100. 50 sebagai nilai minimum dan 100 sebagai nilai maksimum. Berikut adalah rumus konversi untuk mencari bobot alternatf berdasarkan setiap kriteria :

$$
U i j=\frac{(\text { cmax }- \text { cout })}{(\text { cmax }-c \min )}
$$

Dimana:

- $\quad U i j=$ nilai utility kriteria ke-j untuk alternatif ke$\mathrm{i}$

- $\quad$ max $=$ nilai kriteria maksimal

- $\quad c m i n=$ nilai kriteria minimal cout $i=$ nilai kriteria ke-i

7. Menghitung nilai utilitas terhadap semua alternatif berdasarkan setiap kriteria menggunakan formula SMART. Formula yang digunakan dalam SMART adalah:

$$
\text { Maximize } N i=\sum_{j=1}^{k} N W j U i j
$$

Dimana:

- $\quad N w j=$ normalisasi bobot kriteria 
- $\quad U i j=$ nilai utilitas kriteria ke-j untuk alternatif ke-i

- $\quad N i=$ nilai akhir

Maka langkah pertama yang dilakukan yaitu, menentukan kriteria yang digunakan dalam proses perhitungan dengan menggunakan metode SMART. Berikut disajikan kriteria yang digunakan.

Tabel 1 Tabel Kriteria Penilaian Kinerja

Langkah kedua, yaitu memilih alternatif karyawan yang digunakan dalam proses perhitungan. Berikut 4 data alternatif yang dipilih untuk dilakukan perhitungan penilaian kinerja menurut contoh kasus pada tabel 2 .

Tabel 2 Contoh Kasus

\begin{tabular}{|c|c|c|c|c|c|c|c|}
\hline \multicolumn{8}{|c|}{ Contoh Kasus } \\
\hline \multirow{2}{*}{$\begin{array}{c}\text { No } \\
\text {. }\end{array}$} & \multirow{2}{*}{$\begin{array}{c}\mathrm{NI} \\
\mathrm{K}\end{array}$} & \multicolumn{6}{|c|}{ Kriteria } \\
\hline & & $\begin{array}{l}\text { Int } \\
\text { egr } \\
\text { itas }\end{array}$ & $\begin{array}{c}\text { Ker } \\
\text { jasa } \\
\text { ma }\end{array}$ & $\begin{array}{c}\mathrm{Kr} \\
\text { eati } \\
\mathrm{f}\end{array}$ & $\begin{array}{c}\text { Pelayan } \\
\text { an } \\
\text { Pelangg } \\
\text { an }\end{array}$ & $\begin{array}{c}\text { Profesi } \\
\text { onalis } \\
\text { me }\end{array}$ & $\begin{array}{l}\text { Ori } \\
\text { ent } \\
\text { asi } \\
\text { Tuj } \\
\text { uan }\end{array}$ \\
\hline 1 & $\begin{array}{l}131 \\
138 \\
\end{array}$ & $\begin{array}{c}76 . \\
17 \\
\end{array}$ & $\begin{array}{l}87 . \\
67 \\
\end{array}$ & $\begin{array}{l}85 . \\
17 \\
\end{array}$ & 83.83 & 81.67 & $\begin{array}{c}83 . \\
17 \\
\end{array}$ \\
\hline 2 & $\begin{array}{l}140 \\
485 \\
\end{array}$ & $\begin{array}{l}81 . \\
67 \\
\end{array}$ & $\begin{array}{l}81 . \\
83 \\
\end{array}$ & $\begin{array}{c}79 . \\
17 \\
\end{array}$ & 79.67 & 79.50 & $\begin{array}{l}78 . \\
00\end{array}$ \\
\hline 3 & $\begin{array}{l}140 \\
364 \\
\end{array}$ & $\begin{array}{l}87 . \\
50\end{array}$ & $\begin{array}{l}75 . \\
33\end{array}$ & $\begin{array}{l}83 . \\
83\end{array}$ & 87.17 & 87.67 & $\begin{array}{c}84 . \\
00\end{array}$ \\
\hline 4 & $\begin{array}{l}140 \\
365 \\
\end{array}$ & $\begin{array}{l}85 . \\
67\end{array}$ & $\begin{array}{l}82 . \\
00\end{array}$ & $\begin{array}{l}78 . \\
17 \\
\end{array}$ & 87.67 & 80.17 & $\begin{array}{l}85 . \\
83\end{array}$ \\
\hline
\end{tabular}

Langkah ketiga melakukan rangking kriteria berdasarkan kategori kriterianya. Kriteria paling penting yaitu integritas dibandingkan bobotnya dengan kriteria lainnya begitu juga dengan kriteria paling tidak penting yaitu orientasi tujuan juga dibandingkan bobotnya dengan kriteria lainnya. Berikut disajikan perbandingan kriteria berdasarkan kategorinya.

Tabel 3 Perbandingan bobot kriteria integritas dengan kriteria lain

\begin{tabular}{|l|l|l|}
\hline No & Kriteria & Bobot \\
\hline 1. & Integritas & 100 \\
\hline 2. & Kerjasama & 90 \\
\hline 3. & Kreatif & 80 \\
\hline 4. & Pelayanan Pelanggan & 70 \\
\hline 5. & Profesionalisme & 60 \\
\hline 6. & Orientasi Tujuan & 50 \\
\hline \multicolumn{2}{|l}{ Jumlah } & 450 \\
\hline
\end{tabular}

Tabel 4 Perbandingan bobot kriteria orientasi tujuan dengan kriteria lain

\begin{tabular}{|l|l|l}
\hline No & Kriteria & Bobot \\
\hline
\end{tabular}

\begin{tabular}{|l|l|l|}
\hline 1. & Integritas & 85 \\
\hline 2. & Kerjasama & 70 \\
\hline 3. & Kreatif & 65 \\
\hline 4. & Pelayanan Pelanggan & 60 \\
\hline 5. & Profesionalisme & 55 \\
\hline 6. & Orientasi Tujuan & 10 \\
\hline Jumlah & 345 \\
\hline
\end{tabular}

\begin{tabular}{|l|l|}
\hline No. & Kriteria \\
\hline 1. & Integritas \\
\hline 2. & Kerjasama \\
\hline 3. & Kreatif \\
\hline 4. & Pelayanan Pelanggan \\
\hline 5. & Profesionalisme \\
\hline 6. & Orientasi Tujuan \\
\hline
\end{tabular}

Melakukan proses normalisasi untuk masing - masing kriteria berdasarkan kriteria paling penting dan paling tidak penting. Berikut perhitungan yang akan disajikan pada tabel 5 dan 6

Tabel 5 Normalisasi Bobot Kriteria Integritas Dengan Kriteria Lain

\begin{tabular}{|l|l|l|l|}
\hline No & Kriteria & Bobot & $\begin{array}{l}\text { Bobot Relatif } \\
(\mathrm{wj})\end{array}$ \\
\hline 1. & Integritas & $100 / 450$ & 0,22222222 \\
\hline 2. & Kerjasama & $90 / 450$ & 0,2 \\
\hline 3. & Kreatif & $80 / 450$ & 0,17777778 \\
\hline 4. & $\begin{array}{l}\text { Pelayanan } \\
\text { Pelanggan }\end{array}$ & $70 / 450$ & 0,15555556 \\
\hline 5. & Profesionalisme & $60 / 450$ & 0,13333333 \\
\hline 6. & Orientasi Tujuan & $50 / 450$ & 0,11111111 \\
\hline
\end{tabular}

Tabel 6 Normalisasi Bobot Orientasi Tujuan Dengan Kriteria Lain

\begin{tabular}{|l|l|l|l|}
\hline No & Kriteria & Bobot & $\begin{array}{l}\text { Bobot Relatif } \\
(\mathrm{wj})\end{array}$ \\
\hline 1. & Integritas & $85 / 345$ & 0,24637681 \\
\hline 2. & Kerjasama & $70 / 345$ & 0,202898551 \\
\hline 3. & Kreatif & $65 / 345$ & 0,1884058 \\
\hline 4. & $\begin{array}{l}\text { Pelayanan } \\
\text { Pelanggan }\end{array}$ & $60 / 345$ & 0,173913043 \\
\hline 5. & Profesionalisme & $55 / 345$ & 0,15942029 \\
\hline 6. & Orientasi Tujuan & $10 / 345$ & 0,028985507 \\
\hline
\end{tabular}

Langkah selanjutnya, mencari nilai rata rata dari kedua normalisasi bobot kriteria berdasarkan paling penting dan paling tidak penting. Berikut disajikan pada tabel 7.

Tabel 6.12 Bobot Rata - Rata Dari Kedua Normalisasi

\begin{tabular}{|l|l|l|l|}
\hline No & $\begin{array}{l}\text { Bobot Relatif1 } \\
(\mathrm{Wj} 1)\end{array}$ & $\begin{array}{l}\text { Bobot Relatif2 } \\
(\mathrm{Wj} 2)\end{array}$ & $\begin{array}{l}\text { Bobot Rata - Rata } \\
(\mathrm{Wj})\end{array}$ \\
\hline 1. & 0,2222222 & 0,246376812 & 0,234299517 \\
\hline 2. & 0,2 & 0,202898551 & 0,201449275 \\
\hline
\end{tabular}




\begin{tabular}{|l|l|l|l|}
\hline 3. & 0,17777778 & 0,1884058 & 0,1830918 \\
\hline 4. & 0,15555556 & 0,173913043 & 0,1647343 \\
\hline 5. & 0,13333333 & 0,15942029 & 0,146376812 \\
\hline 6. & 0,11111111 & 0,028985507 & 0,070048309 \\
\hline
\end{tabular}

Menghitung nilai alternatif berdasarkan setiap kriteria:

- Nilai integritas: $\operatorname{Max}=87.5, \operatorname{Min}=76.17$

- Nilai kerjasama: $\operatorname{Max}=87.67, \operatorname{Min}=75.33$

- $\quad$ Nilai kreatif: $\operatorname{Max}=85.17$, $\operatorname{Min}=78.17$

- Nilai pelayan pelanggan: $\mathrm{Max}=87.67$, $\mathrm{Min}=$ 79.67

- Nilai profesionalisme: $\operatorname{Max}=87.67, \operatorname{Min}=79.5$

- Nilai orientasi tujuan: $\mathrm{Max}=85.83, \mathrm{Min}=78$

a. NIK: 131138

- $\quad$ Kriteria Integritas $=\frac{87.5-76.17}{87.5-76.17}=1$

- $\quad$ Kriteria Kerjasama $=\frac{87.67-87.67}{87.67-75.33}=0$

- Kriteria Kreatif $=\frac{85.17-85.17}{85.17-78.17}=0$

- Kriteria Pelayanan Pelanggan $=\frac{87.67-83.83}{87.67-79.67}=$ 0.48

- Kriteria Profesionalisme $=\frac{87.67-81.67}{87.67-79.5}=$ 0.734394125

- Kriteria Orientasi Tujuan $=\frac{85.83-83.17}{85.83-78}=$ 0.339719029

b. NIK: 140485

- $\quad$ Kriteria Integritas $=\frac{87.5-81.67}{87.5-76.17}=0.514563107$

- $\quad$ Kriteria Kerjasama $=\frac{87.67-81.83}{87.67-75.33}=0.4732577$

- $\quad$ Kriteria Kreatif $=\frac{85.17-79.17}{85.17-78.17}=0.857142857$

- Kriteria Pelayanan Pelanggan $=\frac{87.67-79.67}{87.67-79.67}=1$

- $\quad$ Kriteria Profesionalisme $=\frac{87.67-79.5}{87.67-79.5}=1$

- Kriteria Orientasi Tujuan $=\frac{85.83-78}{85.83-78}=1$

c. NIK: 140364

- $\quad$ Kriteria Integritas $=\frac{87.5-87.5}{87.5-76.17}=0$

- $\quad$ Kriteria Kerjasama $=\frac{87.67-75.33}{87.67-75.33}=1$

- $\quad$ Kriteria Kreatif $=\frac{85.17-83.83}{85.17-78.17}=0.191428571$

- Kriteria Pelayanan Pelanggan $=\frac{87.67-87.17}{87.67-79.67}=$ 0.0625

- $\quad$ Kriteria Profesionalisme $=\frac{87.67-87.67}{87.67-79.5}=0$

- Kriteria Orientasi Tujuan $=\frac{85.83-84}{85.83-78}=$ 0.233716475

d. NIK: 140365

- $\quad$ Kriteria Integritas $=\frac{87.5-85.67}{87.5-76.17}=0.161518094$

- $\quad$ Kriteria Kerjasama $=\frac{87.67-82}{87.67-75.33}=0.4594814$

- Kriteria Kreatif $=\frac{85.17-78.17}{85.17-78.17}=1$

- Kriteria Pelayanan Pelanggan $=\frac{87.67-87.67}{87.67-79.67}=0$
- Kriteria Profesionalisme $=\frac{87.67-80.17}{87.67-79.5}=$ 0.917992656

- $\quad$ Kriteria Orientasi Tujuan $=\frac{85.83-85.83}{85.83-78}=0$

Menghitung nilai utilitas terhadap semua alternatif berdasarkan setiap kriteria menggunakan formula SMART. Formula yang digunakan adalah Maximize $=\sum_{j=1}^{k} w_{j} \cdot u_{i j}$. Nilai $W j$ diperoleh dari proses normalisasi kriteria dan nilai $U i j$ diperoleh dari perhitungan nilai alternatif untuk setiap kriteria. Berikut disajikan nilai akhir alternatif.

Tabel 6.13 Keputusan Perhitungan Menggunakan Metode SMART

\begin{tabular}{|l|l|l|l|l|}
\hline Kriteria & $\mathbf{1 3 1 1 3 8}$ & $\mathbf{1 4 0 4 8 5}$ & $\mathbf{1 4 0 3 6 4}$ & $\mathbf{1 4 0 3 6 5}$ \\
\hline Integritas & 1 & 0.514563 & 0 & 0.161518 \\
& & 107 & & 094 \\
\hline $\mathbf{W}_{\text {integritas }}$ & 0.234299 & 0.234299 & 0.234299 & 0.234299 \\
& 517 & 517 & 517 & 517 \\
\hline Kerjasama & 0 & 0.473257 & 1 & 0.459481 \\
& & 7 & & 4 \\
\hline $\mathbf{W}_{\text {kerjasama }}$ & 0.201449 & 0.201449 & 0.201449 & 0.201449 \\
& 275 & 275 & 275 & 275 \\
\hline Kreatif & 0 & 0.857142 & 0.191428 & 1 \\
& & 857 & 571 & \\
\hline $\mathbf{W}_{\text {kreatif }}$ & 0.164734 & 0.164734 & 0.164734 & 0.164734 \\
\hline $\begin{array}{l}\text { Pelayanan } \\
\text { Pelanggan }\end{array}$ & 0.48 & 1 & 3 & 3 \\
\hline $\mathbf{W}_{\text {pelayanan }}$ & 0.146376 & 0.146376 & 0.146376 & 0.146376 \\
pelanggan & 812 & 812 & 812 & 812 \\
\hline $\begin{array}{l}\text { Profesionali } \\
\text { sme }\end{array}$ & 0.734394 & 1 & 0 & 0.917992 \\
\hline $\begin{array}{l}\mathbf{W}_{\text {profesionalis }} \\
\text { me }\end{array}$ & 0.125 & & 0.0625 & 0 \\
\hline $\begin{array}{l}\text { Orientasi } \\
\text { Tujuan }\end{array}$ & 0.336376 & 0.146376 & 0.146376 & 0.146376 \\
\hline $\begin{array}{l}\text { Worientasi } \\
\text { tujuan }\end{array}$ & 029 & 812 & 812 & 812 \\
\hline Total & 0,070048 & 0,070048 & 0,070048 & 0,070048 \\
& $\mathbf{0 . 4 4 4 6 6 6}$ & $\mathbf{0 . 7 5 3 9 9 4}$ & $\mathbf{0 . 2 6 3 1 6 5}$ & $\mathbf{0 . 4 4 7 8 7 0}$ \\
\hline
\end{tabular}

Setelah dilakukan perangkingan berdasarkan proses perhitungan dari nilai total masing - masing alternatif, maka metode SMART dapat memberikan rujukan atau rekomendasi untuk mendukung keputusan manajer operasional dalam menentukan karyawan yang mendapatkan kategorti karyawan berprestasi berdasarkan nilai alternatif dan kriteria yang dimiliki oleh masing - masing mahasiswa. Perangkingan diidentifikasi dengan besarnya nilai atau nilai yang paling tinggi adalah alternatif yang memiliki kesempatan paling tinggi untuk menjadi rujukan atau rekomendasi manajer operasional sebagai calon karyawan berprestasi.

\section{Kesimpulan dan Saran}

\subsection{Kesimpulan}

Kesimpulan yang dapat diperoleh dari hasil penelitian Aplikasi Penilaian Kinerja Karyawan Menggunakan metode SMART pada BRI Syariah $\mathrm{KC}$ 
1. Aplikasi penilaian kinerja karyawan menggunakan metode SMART telah dibuat dan dapat berjalan dengan baik secara fungsional dan terbukti efektif dalam mempermudah Manajer dalam melakukan pengambilan keputusan berdasarkan rekomendasi dari aplikasi.

2. Aplikasi ini terbukti efektif dalam mempermudah manajer dalam melakukan proses perhitungan kinerja karyawan.

3. Aplikasi ini memberikan kemudahan dalam pembobotan kriteria sesuai dengan tingkat kepentingan kriterianya untuk menentukan hasil keputusan yang diberikan oleh pihak manajer.

4. Penerapan metode SMART dapat menghasilkan rujukan calon kriteria karyawan berprestasi untuk mendukung pengambilan keputusan oleh bagian manajemen.

5. Metode SMART dapat menerapkan jenis kriteria sesuai dengan pedoman dari pihak manajemen BRI Syariah KC Malang dengan interpretasi skor ujicoba sebesar $93.33 \%$.

\subsection{Saran}

Adapun saran untuk pengembangan aplikasi ini adalah sebagai berikut:

Pengembangan Aplikasi Penilaian Kinerja Karyawan Menggunakan metode SMART selanjutnya, perlu adanya evaluasi kedepan untuk menambah jumlah kriteria yang digunakan yang dinilai dapat mendukung proses pengambilan keputusan untuk berbagai divisi. Perlu adanya pengembangan lebih lanjut terhadap sistem dengan memperhatikan aspek - aspek Interaksi Manusia dan Komputer, serta melakukan perbandingan metode SMART dengan metode SPK lainnya yang mendukung pengambilan keputusan multikriteria dalam aplikasi penilaian kinerja karyawan ini.

\section{Daftar Rujukan}

Arief, R. Pemrograman Web Dinamis Menggunakan PHP dan MySQL, ANDI, Yogyakarta, 2011.

Edwards, W. and Barron, F.H. SMARTS and SMARTER: Improved Simple Methods for Multi Attribute Utility Measurement, Organizational Behaviour and Human Decision Process, 1994.

Kusrini : Konsep dan Aplikasi Sistem Pendukung Keputusan, ANDI, Yogyakarta, 2008.

Rijayana, Iwan. dan Okirindho, Lirien, Sistem Pendukung Keputusan Pemilihan Karyawan Berprestasi Berdasarkan Kinerja Menggunakan Metode Analytic Hierarchy Process, Seminar Nasional Informatika, Yogyakarta, 2012.

Turban, Efraim., Aronson, Jay, E., dan Liang, Ting-Peng : Decision Support Systems and
Intelligent Systems, ANDI, Yogyakarta, 2005. 